\title{
Word MeANing BLindness ReVisited
}

\author{
Matthew A. Lambon Ralph \\ $M R C$ Cognition and Brain Sciences Unit, Cambridge, UK \\ Andrew W. Ellis \\ University of York, UK \\ Karen Sage \\ University of Manchester, UK
}

\begin{abstract}
Lambon Ralph, Sage, and Ellis (1996) described a patient, JO, who had impaired understanding of written words in the presence of normal comprehension of objects and spoken words. She was able to recognise letters and could differentiate w ritten words from nonw ords in lexical decision tasks. JO's ability to read aloud all types of words and non words was also intact. Although JO's understanding with silent reading was compromised, her comprehension was dramatically improved when she was permitted to read words aloud. Lambon Ralph et al. interpreted this disorder as due to a partial disconnection of the visual input lexicon from the semantic system and labelled the disorder "word meaning blindness".

JO's word meaning blindness resulted from a progressive illness that provided us with an opportunity to investigate the pattern of deterioration in this apparently rare form of dyslexia. Over a period of one year we tested her on three occasions with a battery of neuropsychological tasks designed to assess her comprehension across modalities and her ability to read aloud various words, including words with exceptional spelling-to-sound correspondences. The main finding of this longitudinal assessment was a further reduction in her understanding of written words read silently with a preservation of spoken word comprehension. Throughout the period there was little or no change in JO's ability to read aloud words and nonwords, including exception words. The implications of this pattern for theories that emphasise the role of semantics in reading aloud are discussed.
\end{abstract}

Requests for reprints should be addressed to Dr. M. A. Lambon Ralph, MRC Cognition and Brain Sciences Unit, 15 Chaucer Road, Cambridge CB2 2EF, UK. (Tel: 01223 335294; Fax: 01223 359062; E-mail: matt.lambon-ralph@mrcapu.cam.ac.uk).

This study was conducted while the first author was in receipt of a studentship from the Engineering and Physical Sciences Research Council. We would like to thank JO for her continued patience in completing our longitudinal study. We are grateful to Rita Berndt and two anonymous referees for their useful comments on a previous draft of this paper. 


\section{INIROUCTION}

In 1996 we reported a case of "word meaning blindness" (Lambon Ralph et al.,1996). Patient JO was able to read aloud all types of words and differentiate them from non words. Access to meaning was normal for spoken words and from picture input. In contrast, when JO was required to read silently, her understanding of written words was impaired. She was poor at defining written words, matching words to target pictures, and completing written synonym judgement tasks. In word-to-picture matching and word association tasks JO typically chose either the correct target or a semantically related foil, suggesting that the access disorder was only partial. It would appear that, in general, only an impoverished semantic representation could be accessed from written words.

If, however, JO read words aloud, her comprehension was normal. Presumably when JO listened to herself read aloud she could use her intact auditory comprehension processes to understand the words. This recoding of orthographic information via phonology for comprehension is reminiscent of an observation made by Bramwell (1897). He reported a patient with word meaning deafness whose comprehension of spoken words improved when she first wrote down spoken sentences. JO's pattern was, in effect, the reverse of word meaning deafness, and the term "word meaning blindness" was proposed for her performance.

Lambon Ralph et al. (1996) offered the following interpretation for JO's performance in terms of a traditional model of visual word recognition. Errorless letter recognition and lexicaldecision implied that the visual analysis system and visual input lexicon were intact. Normal comprehension of spoken words and pictures suggested that the recognition systems for those input modalities were intact, as was the semantic system. It was suggested that the most likely cause of her word meaning blindness was a partial disconnection between the (intact) visual input lexicon and the (intact) semantic system. In addition, a separate inner speech impairment was demonstrated. This left her unable to recycle the sounds of written words internally, so she could only understand written words by first reading them aloud.

JO's word meaning blindness arose as a result of a progressive brain disorder similar in some ways to the focal atrophy seen in semantic dementia (Hodges, Patterson, Oxbury, \& Funnell, 1992; Snowden, Goulding, \& Neary, 1989). Like those patients, JO's episodic memory (both present and past) seemed to be intact. She was able to complete many nonverbal reasoning tasks, and although she was anomic, her phonology and syntax were normal. Unlike cases of semantic dementia, JO's central semantics were intact and comprehension difficulties were apparent for written words only.

JO was originally tested in a period from March to July 1995. The data gathered at that time formed the basis of our previous report (Lambon Ralph et al., 1996). JO was revisited on a regular basis to follow the decline in her cognitive abilities. This allowed two questions (noted by Lambon Ralph et al., 1996) to be addressed: 
1. How would her comprehension with respect to each modality (pictures, spoken and written words) change over time?

2. If written word comprehension declined further, would surface dyslexia result?

Our first question could be considered to be rather trivial. If a progressive brain disorder impaired a specific function then continued atrophy should lead to an accentuated deficit within the same process. This presumes, however, that the apparent dissociation was not due to a generalised decrement in cognitive performance that appears initially to affect a single function because the process is a complex one and, thus, is sensitive to a nonspecific impairment (Ellis \& Young, 1988; Shallice, 1988). In fact this possibility has been noted and discussed with reference to empirical data for the similar but reversed pattern of comprehension seen in cases of word meaning deafness, where impaired comprehension of spoken words dissociates from intact understanding of written words (Ellis, 1984; Franklin, Howard, \& Patterson, 1994; Franklin \& Lambon Ralph, submitted; Franklin, Turner, Lambon Ralph, Morris, \& Bailey, 1996; Tyler \& Moss, 1997). However, the pattern of word meaning deafness has only been reported for nonprogressive aphasics, which is analogous to single "snap-shot" testing in progressive cases. As JO's word meaning blindness arose from a progressive disease, longitudinal assessment can help to differentiate between the specific versus generalised hypothesis and might highlight the impact of impaired comprehen- sion on other systems such as reading aloud (see following).

On the second question, Lambon Ralph et al. (1996) noted that a semantic access impairment for written words might, according to some theories, lead to surface dyslexia; that is, a tendency to mispronounce words with irregular or exceptional spellings (e.g. colonel $\rightarrow$ "kollonel") while showing a preserved ability to read aloud regular or consistent words, and nonwords. Recent theories have stressed the importance of word meaning in reading aloud, particularly for the successful pronunciation of low-frequency words with exceptional spelling-to-sound correspondences (Patterson \& Hodges, 1992; Patterson, Graham, \& Hodges, 1994; Plaut, McClelland, Seidenberg, \& Patterson, 1996). In these theories there is a "direct", nonsemantic route for the computation of phonology from orthography that is accurate for regular words, nonwords, and high-frequency irregular words. This route is relatively inefficient at reading low-frequency irregular words correctly. Such words are held to rely on support from the semantic system for their correct pronunciation. On this view, the meaning of a target word provides a degree of constraint on output phonology. If, for any reason, the contribution of semantics to reading aloud is reduced sufficiently, the patient should begin to mispronounce low-frequency exception words; that is, the patient should become surface dyslexic. Work within this framework has focused on impairment to the semantic system itself as a cause of reduced semantic contribution to reading, and hence surface 
dyslexia (e.g. Patterson \& Hodges, 1992), or on a reduction in the strength of the links between the semantic system and phonology, which causes a patient to become both anomic and surface dyslexic (Graham, Patterson, \& Hodges, 1995). However, weakening of the links from orthography to semantics, of the sort we have suggested was responsible for JO's word meaning blindness, should also reduce the contribution of semantics to reading aloud, and should therefore result in a patient misreading lowfrequency exception words she no longer understands (cf. Ellis, Lambon Ralph, Morris, $\&$ Hunter, in press).

JO was not surface dyslexic when tested in early 1995. It was possible, however, that sufficient semantic activation remained to sustain errorless reading aloud. We have already discussed the notion that two processes might have different susceptibility to a single deficit. This applies equally here: comprehension will be very sensitive to the impairment between orthography and semantics but reading aloud will be less so. The relative insensitivity of exception word reading accuracy to semantic impairment could be due to the contribution of the direct or nonlexical route, which can provide the pronunciation of many words without assistance from the semantic-lexical route (Hillis \& Caramazza, 1995; Patterson et al., in press; Plaut et al., 1996). Consequently, surface dyslexia might arise when the semantic activation reduced further during the course of JO's progressive disease. We address that possibility in the present paper.

\section{CASEREORT}

JO's personal and medical history is given in Lambon Ralph et al. (1996). She was visited on a regular basis from March 1995 until April 1996. Over this period a number of tests were repeated. The first administration was in March-July 1995. During that time a wide selection of assessments was given, which formed the basis of our previous paper. A subset was re-administered in October 1995 and again in March-April 1996.

Over the course of the year JO's condition was subject to a significant decline. A number of clinical observations are worthy of report. $\mathrm{JO}$, a widow, remained at home and continued her busy social life. Although unable to use a diary (because she couldn't understand the written words), she managed to keep her appointments with those people who visited her. She was able to recall events that had occurred in both the recent and remote past. Although not tested in any formal way, her episodic memory seemed to remain fairly stable.

JO's spontaneous speech became simpler in content and the word-finding difficulties present in March 1995 increased at a rapid rate to a point where she was unable to complete the majority of sentences successfully. This made general conversation very difficult. In addition, she produced a number of overt (and uncorrected) semantic errors in her spontaneous speech, for instance referring to the pears in her garden as "plums".

The longitudinal data is reported in the next three sections. 


\section{Comprehension}

JO was given two tests longitudinally that require access to meaning from either spoken or written words (the written word versions were completed with silent reading). The results are shown in Table 1. The PALPA word-picture matching test (Kay, Lesser, \& Coltheart, 1992) contains 40 trials in which each target picture is presented with a "close" semantic, a "distant" semantic, a visually related, and an unrelated foil. JO's performance on the spoken version remained within the published normal range while her score on the written version declined from 22/ 40 (55\%) in March 1995 to 14/ 40 (35\%) in April 1996 (a score which is only just significantly better than chance: chance cut-off $=13$ / 40 and above). The drop in performance is significant (Binomial: $P=.004$ ), as is the difference between her performance on written and spoken versions in both 1995 and 1996 (1995: McNemar $\chi^{2}=10.6, P<.005 ; 1996$ : McNemar $\left.\chi^{2}=22.0, P<.005\right)$. In March 1995, JO's errors on written word-picture matching were to pick nine close semantic foils, four distant semantic foils, four visually related foils and one unrelated foil. By 1996 this pattern had changed slightly to ten no responses, nine close semantic, four distant semantic, and three visual errors. It is interesting to note that although her overall score had dropped significantly, $50 \%$ of her errors were semantic suggesting that, at least for a subset of items, an impoverished semantic representation was still activated by the written word input.

The within-category word-picture matching tests involve 100 trials, each containing the target picture together with four category coordinate items (e.g. a goat is presented with donkey, deer, horse and cow). On the spoken version her score remained stable (the drop from $96 / 100$ to $93 / 100$ is not statistically significant: Binomial, $P=.23$ ), although in March 1996 it was just outside the range collected from six elderly subjects. On the written version her performance dropped dramatically from 83/ 100 to 37/ 100 (McNemar, $\chi^{2}=34.9, P$ $<.005$; chance cut-off $=28 / 100$ and above) . For each of the three testing sessions the difference between the scores in spoken and written versions was significant (March 1995: McNemar $\chi^{2}=8.5, P<.005$; October 1995: McNemar $\chi^{2}=$ 15.4, $P$ <.005; March 1996: McNemar $\chi^{2}=48.8$, $P<.005)$.

It was demonstrated in 1995 that JO's performance on written word comprehension tasks improved to a normal level when she was permitted to read the words aloud (Lambon Ralph et al., 1996). This recoding effect was assessed longitudinally using the PALPA word association task. In this test the patient is required to pick which of four words is closest in meaning to a target item (e.g. fog). The correct response (e.g. mist) is accompanied with a semantically related foil (e.g. steam) and two unrelated items (which are semantically related to each other: e.g. bolt and lock). Half the items relate to concrete items and the other half to abstract concepts. The results are shown in Table 1.

In the silent condition, JO's performance for the concrete items remained unchanged (but outside the normal range) while her score for the abstract items reduced to just $2 / 15$ (13\%: a 
Table 1. Jo's Comprehension of Spoken Words, Written Words, and Pictures

\begin{tabular}{|c|c|c|c|c|c|c|}
\hline Task/Stimulus Types & $\begin{array}{l}\text { Reading } \\
\text { Condition }\end{array}$ & $\begin{array}{r}\text { No. of } \\
\text { Items }\end{array}$ & $\begin{array}{l}\text { March } \\
1995\end{array}$ & $\begin{array}{c}\text { October } \\
1995\end{array}$ & $\begin{array}{l}\text { March } \\
1996\end{array}$ & $\begin{array}{l}\text { Normal } \\
\text { Control }\end{array}$ \\
\hline $\begin{array}{l}\text { PALPA spoken word-picture } \\
\text { matching }\end{array}$ & & 40 & $90 \%$ & NT & $95 \%$ & $88-100^{a}$ \\
\hline $\begin{array}{l}\text { PALPA written word-picture } \\
\text { matching }\end{array}$ & Silent & 40 & $55 \%$ & NT & $35 \%$ & $88-100^{a}$ \\
\hline $\begin{array}{l}\text { Within-category spoken word } \\
\text { picture matching }\end{array}$ & & 100 & $96 \%$ & $96 \%$ & $93 \%$ & $96-100^{b}$ \\
\hline $\begin{array}{l}\text { Within-category written } \\
\text { word-picture matching }\end{array}$ & Silent & 100 & $83 \%$ & $77 \%$ & $37 \%$ & $96-100^{b}$ \\
\hline PALPA word-association & & & & & & \\
\hline High imageability & Silent & 15 & $33 \%$ & $40 \%$ & $40 \%$ & $73-100^{a}$ \\
\hline Low imageability & Silent & 15 & $47 \%$ & $47 \%$ & $13 \%$ & $60-100^{a}$ \\
\hline High imageability & Aloud & 15 & $66 \%$ & $73 \%$ & $66 \%$ & $73-100^{a}$ \\
\hline Low imageability & Aloud & 15 & $80 \%$ & $53 \%$ & $53 \%$ & $60-100^{a}$ \\
\hline Pyramids \& Palm Trees Test & & & & & & \\
\hline Pictures & - & 52 & $92 \%$ & $75 \%$ & $81 \%$ & $94-100^{a}$ \\
\hline
\end{tabular}

score no better than chance). When permitted to read the items aloud, her performance increased significantly on all three occasions (March 1995: Binomial, $P=.001$; October 1995: Binomial, $P=.02$; March, 1996: Binomial, $P=$ .006). Her understanding of written words read aloud (an indirect test of spoken word comprehension) was only one point outside the normal range both for concrete and abstract items.

The all-picture version of the Pyramids and Palm Trees Test (Howard \& Patterson, 1992) requires the patient to chose which of two pictures (e.g. a palm tree or a fir tree) is associatively linked to a target picture (e.g. a pyramid). In March 1995, JO's performance on this test was one point outside the normal range (see Table 1). Her scores in October 1995 and
March 1996 fell further below the normal range. The difference between her scores in March 1995 and October 1996 is significant $\left(\right.$ McNemar $\left.\chi^{2}=4.3, P<.05\right)$, although the difference between her scores in March 1995 and March 1996 does not achieve significance (McNemar $\chi^{2}=2.1$, n.s.).

\section{Peading Aloud}

JO's longitudinal reading performance is shown in Table 2. Her reading accuracy changed little over the intervening year. The words used by Strain, Patterson, and Seidenberg (1995) orthogonally manipulate regularity, imageability, and frequency in List 1, and imageability and regularity for a set of low-frequency words in List 2. JO was able to read 
Table 2. JO's Reading Aloud

\begin{tabular}{lrrrrr}
\hline Task & $\begin{array}{r}\text { No. of } \\
\text { Items }\end{array}$ & $\begin{array}{c}\text { March } \\
1995\end{array}$ & $\begin{array}{c}\text { October } \\
1995\end{array}$ & $\begin{array}{c}\text { March } \\
1996\end{array}$ & $\begin{array}{c}\text { Normal } \\
\text { Controls }\end{array}$ \\
\hline Strain et al.: List 1 & 96 & $100 \%$ & $99 \%$ & $99 \%$ & $98-100^{a}$ \\
Strain et al.: List 2 & 64 & $95 \%$ & $97 \%$ & $97 \%$ & $92-98^{b}$ \\
Levels of regularity & 120 & $97 \%$ & $98 \%$ & $93 \%$ & $95-100^{b}$ \\
PALPA nonwords & & & & & \\
$\quad$ 3 letters & 6 & $67 \%$ & $83 \%$ & $100 \%$ & $67-100^{a}$ \\
4 letters & 6 & $67 \%$ & $100 \%$ & $100 \%$ & $83-100^{a}$ \\
5 letters & 6 & $83 \%$ & $100 \%$ & $83 \%$ & $67-100^{a}$ \\
6 letters & 6 & $100 \%$ & $100 \%$ & $83 \%$ & $67-100^{a}$ \\
\hline
\end{tabular}

${ }^{a}$ Published norms (2 SD cut-off).

${ }^{b}$ Collected from 10 elderly control subjects.

these words as well as normal control subjects. The same pattern was found for nonword reading (PALPA Test No. 36: Kay et al., 1992). Only on the "Levels of Regularity" list (Shallice, Warrington, \& McCarthy, 1983) was there a very small (and nonsignificant) drop in reading accuracy.

\section{Naming}

The clinical indications of increasing anomia were confirmed by three tests of naming and a category fluency task (see Table 3). JO's pre- dominant naming errors were either failures to respond or semantic errors (category co-ordinate or superordinate names). Her decline in performance was most apparent for the Boston Naming Test (Kaplan, Goodglass, \& Weintraub, 1976), her score reducing from $40 / 60$ to $28 / 60\left(66 \% \rightarrow 47 \%\right.$ : McNemar $\left.\chi^{2}=7.6, P<.01\right)$ and on a naming-to-definition task (50 common object and animal targets given simple dictionary-style definitions containing perceptual and associative/ functional information; e.g. dog, "a domesticated, four-legged mammal which has fur and barks"), her accuracy

Table 3. JO's Naming and Category Fluency

\begin{tabular}{|c|c|c|c|c|c|}
\hline Task & $\begin{array}{l}\text { No. of } \\
\text { Items }\end{array}$ & $\begin{array}{c}\text { March } \\
1995\end{array}$ & $\begin{array}{c}\text { October } \\
1995\end{array}$ & $\begin{array}{c}\text { March } \\
1996\end{array}$ & $\begin{array}{l}\text { Normal } \\
\text { Controls }\end{array}$ \\
\hline Boston Naming Test & 60 & $66 \%$ & $63 \%$ & $47 \%$ & $82-98^{a}$ \\
\hline Naming 240 line drawings & 240 & $77 \%$ & $71 \%$ & $69 \%$ & $95-100^{b}$ \\
\hline Naming to definition & 50 & NT & $74 \%$ & $46 \%$ & $94-100^{b}$ \\
\hline Category fluency (8 categories) & - & 40 & 28 & 18 & $\begin{array}{l}\text { Mean } 113.7 \\
\text { SD } 19.4^{a}\end{array}$ \\
\hline
\end{tabular}

${ }^{a}$ Published norms.

${ }^{b}$ Collected from six elderly control subjects.

$\mathrm{NT}=$ not tested. 
dropped from $37 / 50$ to $23 / 50(74 \% \rightarrow 46 \%$; McNemar $\left.\chi^{2}=9.4, P<.005\right)$. On the set of 240 simple line drawings, her naming deteriorated slightly from $184 / 240$ to $166 / 240$ (77\% $\rightarrow 69 \%$ : McNemar $\left.\chi^{2}=14.5, P<.005\right)$. JO's progressive anomia also lead to a decline in performance on a test of category fluency (Hodges et al., 1992).

The notable differential between JO's increasing anomia and her intact spoken word-picture matching performance is very similar to the pattern described by Graham, Patterson, and Hodges (1995) for their patient FM (albeit FM's anomia was considerably deeper). Although FM was first described as a semantic dementia patient with impaired comprehension and naming (see Hodges et al., 1992), over time Graham et al. were able to demonstrate a pattern of "progressive pure anomia"- increasing word-finding difficulties for picture naming and category fluency without a corresponding change in her comprehension scores.

\section{disassan}

The most obvious change in JO's data was a dramatic reduction in her ability to understand written words. There was no corresponding change in her understanding of spoken words and only a small decline for picture comprehension. There was, in addition a substantial increase in JO's anomia. The recoding effect (increased comprehension of written words when read aloud) remained apparent in 1996.
JO's word meaning blindness was not only a stable but also an increasing feature of her progressive illness. This finding allows us to reject the possibility noted by Lambon Ralph et al. (1996) that JO's pattern of performance might have become more like that seen in semantic dementia, where understanding from all modalities is equally compromised. The accentuated dissociation between written and spoken word comprehension allowed us to address the alternative hypothesis, suggested in the Introduction, that the difference was in fact due to a relative sensitivity of written word comprehension to a more general cognitive impairment. We can now argue against this on two grounds. First, JO and patients with word meaning deafness form a double dissociation between written and spoken comprehension, thus implying two quite separate routes into conceptual knowledge. Second, JO's progressive illness led to a dramatic reduction in her comprehension of written words with no apparent change to her comprehension of the same words when they were presented orally.

A subset of tasks was included in the longitudinal battery to test the theory that a semantic impairment would lead to surface dyslexia. In variants of this theory (cf. Patterson \& Hod ges, 1992; Patterson et al., 1994; Plaut et al., 1996) the influence of semantic representations on phonological computation from orthography can be reduced in three different ways: as a result of an impairment to semantic knowledge itself, as a consequence of damage to the link between orthographic and semantic representations, or to the link between semantics 
and output phonology. Between 1995 and 1996, JO's semantic route had been compromised even further: both her word meaning blindness and anomia had increased. Despite these considerable changes, JO's reading aloud had not declined from its 1995 levels. This notable difference can be seen clearly if JO's percentage scores for the assessments are plotted on the same axes (see Fig. 1). In this regard, JO's data add to the small number of patients for whom exception word reading remains intact despite relatively poor comprehension (Cipolotti \& Warrington, 1995; Lambon Ralph, Ellis, \& Franklin, 1995; Raymer \& Berndt, 1996; Schwartz, Saffran Marin, 1980).

In its current formulations (even in computational form: Plaut et al., 1996), the theory that semantics contributes to the reading aloud of low-frequency exception words does not make any clear predictions regarding the quantity or quality of semantic activation required for a given level of reading performance (Lambon Ralph et al., 1995). Funnell (1996) argued that her patient EP regularised an exception word only when no meaning remained available. Reading accuracy was significantly associated with comprehension when assessed by a word-picture matching task containing the target and an unrelated foil; there was no association if the foil was replaced with a close semantic distractor. To make matters more complicated, it should be noted that other patients have demonstrated a significant association between reading accuracy and word-picture matching in which the foils are all within the same category (Graham, Hodges, \& Patterson, 1994; Hillis \&
Caramazza, 1995). This could suggest that the relationship between semantics and reading aloud varies from individual to individual (cf. Plaut, 1997), so that some subjects require relatively intact comprehension (and regularise words when they make close-semantic comprehension errors) whereas others need very little (e.g. EP) or perhaps none at all. Although the individual differences hypothesis fits this pattern of results, it is not clear that there is any existing or potential data which could falsify the theory (see Lambon Ralph et al., 1995).

Despite very poor word-picture matching performance, $50 \%$ of JO's errors were semantically related to the target items. This indicates that for a number of written words an impoverished semantic representation was still being activated that might have provided sufficient support for the "direct" orthography-to-phonology route. Hence JO's data show that accurate exception word reading can occur in the presence of impaired semantic access but do not address the question of whether exception word reading can survive a complete block to semantics from orthography. It is possible that in time, when JO's written word comprehension had declined even further, a surface dyslexia pattern may have emerged. Such a result could arise if a decline in conceptual knowledge is paired with a much slower, non-linear decrement in reading accuracy (see Plaut et al., 1996, Fig. 25). We would suggest that future longitudinal studies, which continue beyond the stage we were able to assess JO, should be able to estimate the relative gradients of reading and comprehension deterioration and to confirm whether the rate of decline varies from 

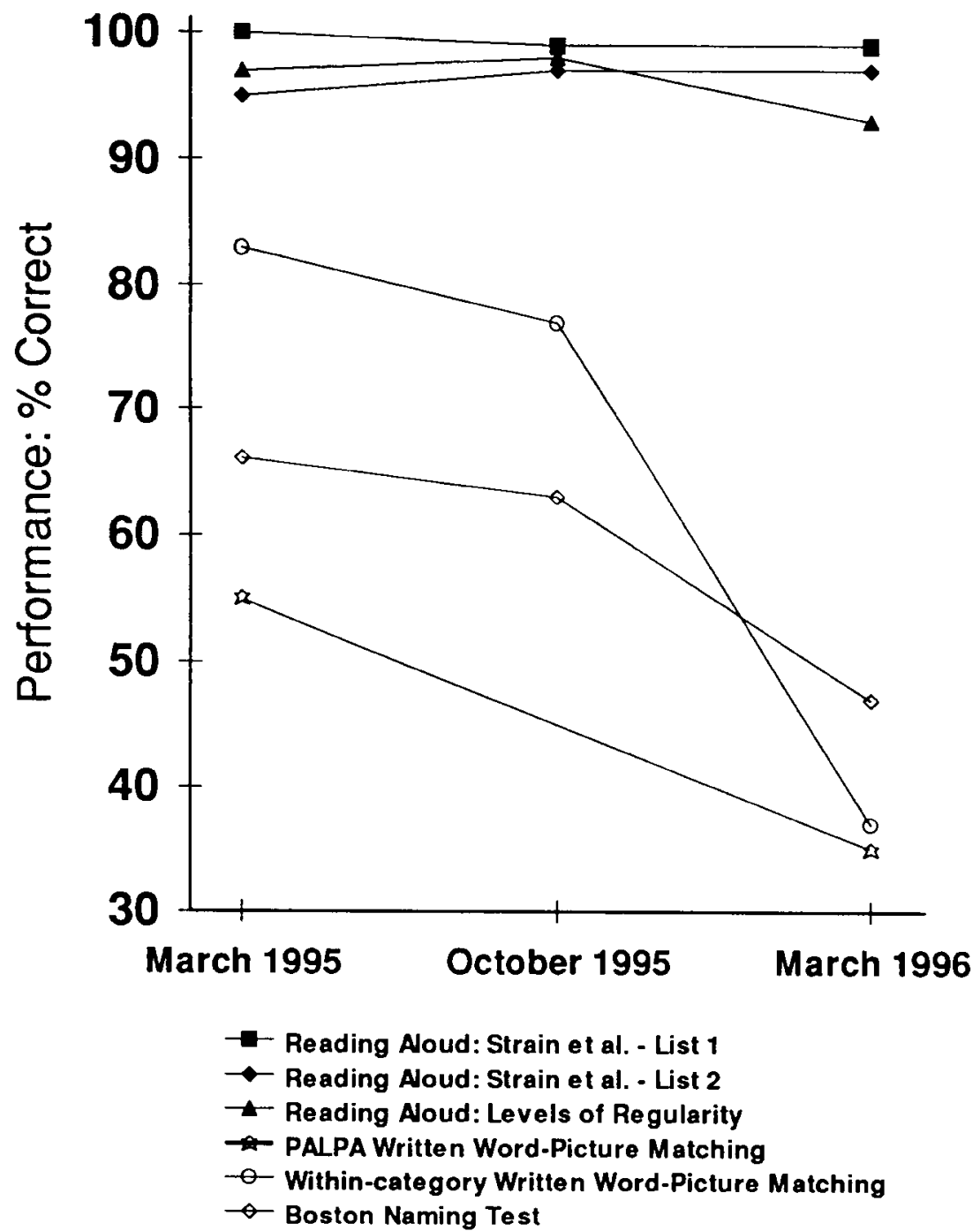

Fig. 1. JO's reading aloud vs. written word comprehension and picture naming. 
individual to individual (Plaut, 1997) or if, in fact, that the two processes can classically dissociate (Shallice, 1988) from each other, given the prediction that the relationship between them is a subtle one.

Manuscript received 3 March 1997 Revised manuscript received 14 January 1998 Manuscript accepted 14 January 1998

\section{PEAENCES}

Bramwell, B. (1897). Illustrative cases of aphasia. Lancet, 1, 1256-1259.

Cipolotti, L., \& Warrington, E.K. (1995). Semantic memory and reading abilities: A case report. Journal of the International Neuropsychological Society, 1, 104-110.

Ellis, A.W. (1984). Introduction to Byrom Bramwell's (1897) case of word meaning deafness. Cognitive Neuropsychology, 1, 245-248.

Ellis, A.W., Lambon Ralph, M.A., Morris, J., \& Hunter, A. (in press). Surfacedyslexia:Description, treatment and interpretation. In E. Funnell (Ed.), Casestudies in the neuropsychology of reading. Hove, UK: Psychology Press.

Ellis, A.W., \& Young, A.W. (1988). Human cognitive neuropsychology. Hove, UK: Lawrence Erlbaum Associates Ltd.

Franklin, S., How ard, D., \& Patterson, K. (1994). Abstract word meaning deafness. Cognitive Neuropsychology, 11, 1-34.

Franklin, S., \& Lambon Ralph, M.A. (submitted). Word meaning deafness: A reply to Tyler and Moss. Cognitive Neuropsychology.

Franklin, S., Turner, J., Lambon Ralph, M.A., Morris, J., \& Bailey, P.J. (1996). A distinctive case of word meaning deafness? Cognitive Neuropsychology, 13, 1139-1162.

Funnell, E. (1996). Response biases in oral reading: An account of the co-occurrence of surface dyslexia and semantic dementia. Quarterly Journal of Experimental Psychology, 49, 417-446.
Graham, K.S., Hodges, J.R., \& Patterson, K.E. (1994). The relationship between comprehension and oral reading in progressive fluent aphasia. Neuropsychologia, 32, 299-316.

Graham, K.S., Patterson, K., \& Hodges, J.R. (1995). Prog ressive pure anomia: Insufficient activation of phonolog y by meaning. Neurocase, 1, 25-38.

Hillis, A.E., \& Caramazza, A. (1995). Converging evidence for the interaction of semantic and sublexical phonolog ical information in accessing lexical representations for spoken output. Cognitive Neuropsychology, 12, 187-227.

Hodges, J.R., Patterson, K., Oxbury, S., \& Funnell, E. (1992). Semantic dementia: Progressive fluent aphasia with temporal lobe atrophy. Brain, 115, 1783-1806.

Howard, D., \& Patterson, K. (1992). The Pyramids and Palm Trees Test: A test of semantic access from words and pictures. Bury St. Edmunds, UK: Thames Valley Test Company.

Kaplan, E., Goodglass, H., \& Weintraub, S. (1976). The Boston Naming Test. Boston, MA: Veterans Administration.

Kay, J., Lesser, R., \& Coltheart, M. (1992). Psycholinguistic Assessments of Language Processing in Aphasia (PALPA). Hove, UK: Lawrence Erlbaum Associates Ltd.

Lambon Ralph, M.A., Ellis, A.W., \& Franklin, S. (1995). Semantic loss without surface dyslexia. Neurocase, 1, 363-369.

Lambon Ralph, M.A., Sage, K., \& Ellis, A.W. (1996). Word meaning blindness: A new form of acquired dyslexia. Cognitive Neuropsychology, 13, 617.

Patterson, K., Graham, N., \& Hodges, J.R. (1994). The impact of semantic memory loss on phonolog ical representations. Journal of Cognitive Neuroscience, 6, 57-69.

Patterson, K., \& Hodges, J.R. (1992). Deterioration of word meaning: Implications for reading. Neuropsychologia, 30, 1025-1040.

Patterson, K., Plaut, D.C., McClelland, J.L., Seidenberg, M.S., Behrmann, M., \& Hodges, J.R. (in press). Connections and disconnections: A connectionist account of surface dyslexia. In J. Reggia, R. Berndt, \& E. Ruppin (Eds.), Neural 
modeling of cognitive and brain disorders. New York: World Scientific.

Plaut, D.C. (1997). Structure and function in the lexical system; Insights from distributed models of naming and lexical decision. Languageand Cognitive Processes, 12, 765-805.

Plaut, D.C., McClelland, J.L., Seidenberg, M.S., \& Patterson, K. (1996). Understanding normal and impaired word reading: Computational principles in quasi-regular domains. Psychological Review, 103, 56-115.

Raymer, A.M., \& Berndt, R.S. (1996). Reading lexically without semantics: Evidence from patients with probable Alzheimer's disease. Journal of the International Neuropsychological Society, 2, 340-349.

Schwartz, M.F., Saffran, E.M., \& Marin, O.S.M. (1980). Fractionating the reading process in dementia: Evidence for word-specific print-tosound associations. In M. Coltheart, K. Patterson,
\& J.C. Marshall (Eds.), Deep dyslexia. London: Routledge \& Kegan Paul.

Shallice, T. (1988). From neuropsychology to mental structure. Cambridge: Cambridge University Press.

Shallice, T., Warrington, E.K., \& McCarthy, R. (1983). Reading without semantics. Quarterly Journal of Experimental Psychology, 35a, 111-138.

Snowden, J.S., Goulding, P.J., \& Neary, D. (1989).

Semantic dementia: A form of circumscribed cerebral atrophy. Behavioural Neurology, 2, 167-182.

Strain, E., Patterson, K., \& Seidenberg, M.S. (1995). Semantic effects in single-word naming. Journal of Experimental Psychology Learning, Memory, and Cognition, 21, 1140-1154.

Tyler, L.K., \& Moss, H.E. (1997). Imageability and category-specificity. Cognitive Neuropsychology, 14, 293-318. 